\title{
Eight and 12 week courses of cyclophosphamide in nephrotic syndrome
}

\author{
N Ueda, K Kuno, S Ito
}

\begin{abstract}
Seventy three children with steroid dependent minimal change nephrotic syndrome were randomly allocated to receive treatment with cyclophosphamide $(2 \mathrm{mg} / \mathrm{kg} /$ day $)$ for either eight or 12 weeks, in combination with prednisolone. All patients had previously relapsed while the dosage was being reduced or within 14 days of discontinuing prednisolone in the six months before receiving cyclophosphamide treatment (steroid dependent), and had severe steroid toxicity. Thirty two patients were treated with cyclophosphamide for eight weeks, and 41 for 12 weeks. There were no differences between the two groups in age at onset of nephrosis or entry into the study, sex ratio, duration of nephrosis, number of relapses before entry, and follow up period after entry. The relapse free rate of patients treated for eight weeks (25\%) was similar to that of those treated for 12 weeks (24\%) five years after stopping the treatment, and the mean relapse free interval and the sparing effect of cyclophosphamide (if any) on subsequent treatment with steroids did not differ between the groups. We conclude that cyclophosphamide should be used for no longer than eight weeks at a dose of $2 \mathrm{mg} / \mathrm{kg} /$ day in children with steroid dependent minimal change nephrotic syndrome.
\end{abstract}

Cyclophosphamide has been widely used in combination with corticosteroids (steroids) to treat children with frequently relapsing nephrotic syndrome and produces a long remission. ${ }^{1-10}$ The side effects of cyclophosphamide such as bone marrow suppression, ${ }^{211}$ gonadal toxicity, ${ }^{12}$ and possibly oncogenicity ${ }^{4}$ seem to be dose related. If the drug is to be used in frequently relapsing nephrotic patients, we must, therefore, use the lowest effective dosage, keeping the risk of long range toxicity as low as possible. Previous studies suggested that children with frequently relapsing nephrotic syndrome without steroid dependence could be more successfully treated with cyclophosphamide than those with steroid dependence. ${ }^{89}$ Other authors have compared eight week and 12 week courses of cyclophosphamide, and reported that a 12 week course of treatment is more likely to result in sustained remission in steroid dependent nephrotic patients. ${ }^{10}$ Despite the results of this relatively small study, it is still uncertain whether cyclophosphamide is more effective when given for 12 weeks than for eight weeks to treat steroid dependent nephrotic patients with minimal change.
The present prospective study was designed to determine whether eight week or 12 week courses of cyclophosphamide at a dose of $2 \mathrm{mg} /$ $\mathrm{kg}$ /day were more effective in a large number of children with steroid dependent minimal change nephrotic syndrome who had severe steroid toxicity.

\section{Patients and methods}

From February 1975 to August 1988, 73 children ( 54 boys) with steroid dependent minimal change nephrotic syndrome confirmed by the classic clinical and laboratory features and histological examination of a renal biopsy specimen were treated with a combination of prednisolone and cyclophosphamide. ${ }^{3}$ All patients had relapsed while the dose of prednisolone was being reduced, or within 14 days of discontinuing prednisolone, in the six months before cyclophosphamide treatment (steroid dependent). They developed at least two of the following features of steroid toxicity due to the long term steroid treatment: arrest of growth, hypertension, gross cushingoid appearance, osteoporosis, psychosis, diabetes, cataracts, and glaucoma.

Because of steroid dependence and severe steroid toxicity, each patient was randomly allocated to one of the following two treatment regimens of cyclophosphamide after remission had been induced: $2 \mathrm{mg} / \mathrm{kg} /$ day of cyclophosphamide for eight weeks (total dosage, $112 \mathrm{mg} / \mathrm{kg}$ ), or the same daily dose for 12 weeks (total dosage, $168 \mathrm{mg} / \mathrm{kg}$ ). None of the patients had received any relevant drugs other than prednisolone before the course of cyclophosphamide. Informed consent was obtained from the parents of each patient.

The initial episode of the nephrotic syndrome and all relapses during the period of observation (proteinuria $\geqslant 40 \mathrm{mg} / \mathrm{hour} / \mathrm{m}^{2}$ for three consecutive days) were treated with prednisolone in divided doses of $60 \mathrm{mg} / \mathrm{m}^{2}$ per day for four weeks, with the dose being tapered by 5 to 10 $\mathrm{mg} / \mathrm{m}^{2}$ every two weeks during the next three to four months. Those patients who had milder degrees of proteinuria (greater than $4 \mathrm{mg} / \mathrm{hour} /$ $\mathrm{m}^{2}$ but less than $40 \mathrm{mg} /$ hour $/ \mathrm{m}^{2}$ ) were managed with the previous maintenance dose of prednisolone for one to two weeks, the dose either being increased to $60 \mathrm{mg} / \mathrm{m}^{2} /$ day if remission ( $<4 \mathrm{mg} / \mathrm{hour} / \mathrm{m}^{2}$ for three consecutive days) was not achieved, or decreased after at least one week of remission of proteinuria.

During the course of cyclophosphamide the white cell count was estimated weekly, and the drug was discontinued if the total count was 
below $4 \cdot 0 \times 10^{9} / 1$. Cyclophosphamide was reinstituted at the previous dosage level after the white blood cell count had increased to $4.0 \times 10^{9} / 1$ or more.

To assess the effect of the two regimens of cyclophosphamide the following variables were compared: the relapse free rate and relapse free interval after cyclophosphamide treatment, the mean number of relapses, the mean cumulative dosage of prednisolone, and the mean total time not taking prednisolone before and after the course of cyclophosphamide. Acute side effects such as leucopenia, thrombocytopenia, haemorrhagic cystitis, alopecia, and infections, were recorded.

Results were expressed as mean (SD). $\chi^{2}$ analysis was used to analyse the differences between groups is sex ratio, relapse free rate after cyclophosphamide treatment, and incidence of toxic reactions to the drug. The two tailed Student's $t$ test was used to analyse the means of other variables, and the cumulative percentage of remission after cyclophosphamide treatment was plotted by the time to relapse curve, as previously described. ${ }^{6} 13$

\section{Results}

Seventy three patients entered into the study; 32 patients were treated with cyclophosphamide for eight weeks, and the remaining 41 were treated for 12 weeks. The mean ages at onset of nephrosis and at entry into the study, sex ratio, the mean duration of nephrosis before entry, and the mean period of follow up after cyclophosphamide treatment were similar in the two groups (table 1). There were no significant differences between the two groups in the mean number of relapses or the mean cumulative dosage of prednisolone before entry.

Only eight of the 32 patients $(25 \%)$ treated with cyclophosphamide for eight weeks, and 10

Table 1 Details of patients studied. Values are expressed as mean (SD) except where otherwise stated

\begin{tabular}{lcc}
\hline & $\begin{array}{c}\text { Cyclophosphamide } \\
\text { for eight weeks } \\
(n=32)\end{array}$ & $\begin{array}{l}\text { Cyclophosphamide } \\
\text { for 12 weeks } \\
(n=41)\end{array}$ \\
\hline Male:female ratio & $26: 6$ & $28: 13$ \\
Age at onset of nephrosis (years) & $6 \cdot 0(3 \cdot 4)$ & $6 \cdot 4(3 \cdot 7)$ \\
Age at entry into the study (years) & $7 \cdot 7(3.7)$ & $7 \cdot 8(3 \cdot 7)$ \\
Duration of nephrosis before entry (months) & $18 \cdot 8(20 \cdot 9)$ & $19 \cdot 2(25 \cdot 3)$ \\
Length of follow up after entry (months) & $66 \cdot 2(50 \cdot 6)$ & $63 \cdot 1(33 \cdot 7)$ \\
No of relapses before entry (/patient/year) & $4 \cdot 5(1 \cdot 8)$ & $5 \cdot 1(2 \cdot 3)$ \\
Cumulative dosage of prednisolone before & $19 \cdot 3(9 \cdot 6)$ & $18 \cdot 5(8 \cdot 0)$ \\
entry (mg/kg/month follow up) & & \\
\hline
\end{tabular}

of the 41 patients (24\%) treated for 12 weeks were still in remission at the end of the period of observation (table 2 ). In patients who had not relapsed the mean interval was $76.5(38.6)$ and $71.3(23.3)$ months in those treated for eight weeks and 12 weeks respectively, and the difference was not significant. In patients who relapsed after cyclophosphamide treatment, the mean interval without relapse was $4.9(4 \cdot 6)$ and $4.0(5 \cdot 4)$ months for those treated for eight weeks and 12 weeks, respectively. All but one of the relapses after cyclophosphamide occurred within two years of discontinuing treatmentthe longest was a patient treated for 12 weeks who relapsed at 29 months. No significant differences were noted between the groups of relapsed patients in the mean number of relapses, the mean cumulative dosage of prednisolone, or the mean total time not taking prednisolone after the course of cyclophosphamide.

The figure shows the 'time to relapse' curves of patients treated with eight week and 12 week courses of cyclophosphamide. ${ }^{613}$ There was no significant difference in the cumulative percentage of remission at the end of five years after discontinuing cyclophosphamide.

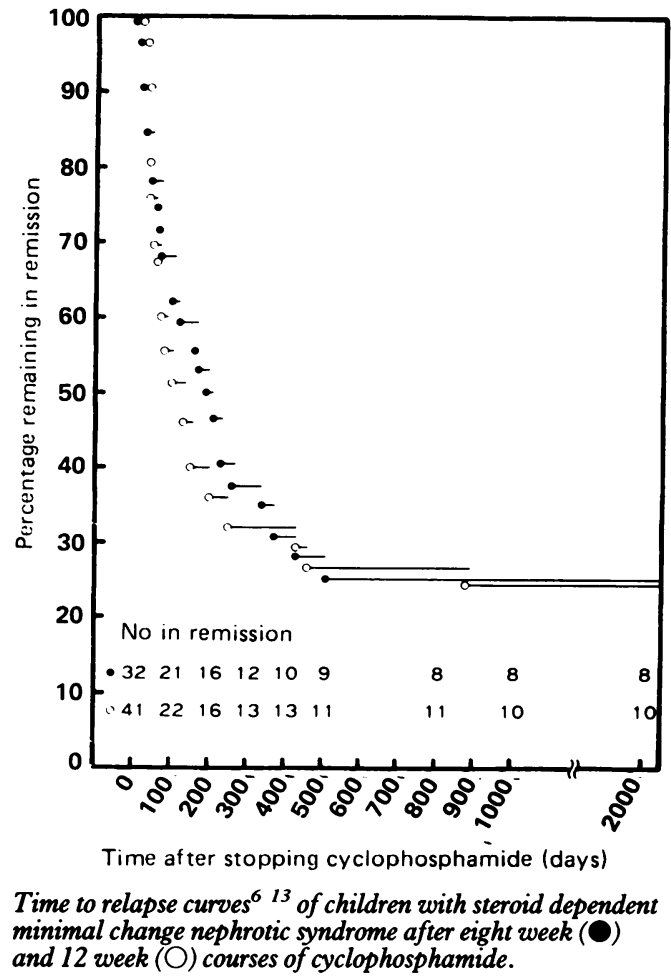

Table 2 Clinical data of patients after treatment with cyclophosphamide. Values are expressed as mean (SD)

\begin{tabular}{|c|c|c|c|c|}
\hline & \multicolumn{2}{|c|}{$\begin{array}{l}\text { Cyclophosphamide for } \\
\text { eight weeks }\end{array}$} & \multicolumn{2}{|c|}{$\begin{array}{l}\text { Cyclophosphamide for } \\
12 \text { weeks }\end{array}$} \\
\hline & $\begin{array}{l}\text { No relapse } \\
(n=8)\end{array}$ & $\begin{array}{l}\text { Relapse } \\
(n=24)\end{array}$ & $\begin{array}{l}\text { No replase } \\
(n=10)\end{array}$ & $\begin{array}{l}\text { Relapse } \\
(n=31)\end{array}$ \\
\hline \multirow{3}{*}{$\begin{array}{l}\text { Interval without relapse after entry (months) } \\
\text { No of relapses (/patient/year): } \\
\text { Before entry } \\
\text { After entry } \\
\text { Cumulative dosage of prednisolone } \\
\text { (mg/kg/month follow up): } \\
\text { Before entry } \\
\text { After entry }\end{array}$} & $76 \cdot 5(38 \cdot 6)$ & $4 \cdot 9(4 \cdot 6)$ & $71 \cdot 3(23 \cdot 3)$ & $4 \cdot 0(5 \cdot 4)$ \\
\hline & ${ }_{0}^{4 \cdot 4(2 \cdot 6)}$ & $\begin{array}{l}4.5(1.5) \\
2.9(1.6)\end{array}$ & $\begin{array}{l}4 \cdot 5(2 \cdot 0) \\
0\end{array}$ & $\begin{array}{l}5 \cdot 3(2 \cdot 3) \\
3 \cdot 5(3 \cdot 8)\end{array}$ \\
\hline & $\begin{array}{r}16 \cdot 0(8 \cdot 2) \\
1 \cdot 2(0 \cdot 3)\end{array}$ & $\begin{array}{l}20 \cdot 5(9 \cdot 9) \\
11 \cdot 1(8 \cdot 2)\end{array}$ & $\begin{array}{r}16.9(6.5) \\
0.8(0.5)\end{array}$ & $\begin{array}{l}19 \cdot 1(8 \cdot 5) \\
12 \cdot 1(8 \cdot 5)\end{array}$ \\
\hline $\begin{array}{l}\text { Total time not taking prednisolone (months): } \\
\text { Before entry } \\
\text { After entry }\end{array}$ & $\begin{array}{l}2 \cdot 4(4 \cdot 5) \\
69 \cdot 9(44 \cdot 0)\end{array}$ & $\begin{array}{r}2 \cdot 0(2 \cdot 9) \\
33 \cdot 9(51 \cdot 3)\end{array}$ & $\begin{aligned} & 1 \cdot 2(2 \cdot 8) \\
& 68 \cdot 6(21 \cdot 3)\end{aligned}$ & $\begin{aligned} 3 \cdot 2(5 \cdot 6) \\
25 \cdot 8(34 \cdot 7)\end{aligned}$ \\
\hline
\end{tabular}


As there was no difference in outcome between the groups, the clinical features were compared between patients who relapsed $(n=55)$ and those who did not $(n=18)$. There were no significant differences between these groups in sex ratio, age at onset of nephrosis, duration of nephrosis, and the number of relapses before cyclophosphamide treatment. Patients who did not relapse, however, were significantly older when they entered the study $(9 \cdot 3(4 \cdot 3)$ years) than those who did $(7 \cdot 3(3 \cdot 3)$ years), $(\mathrm{p}<0.05)$.

Nine of the 32 patients treated for eight weeks became leucopenic compared with 14 of the 41 patients treated for 12 weeks. A short interruption of the treatment was necessary in only eight patients, and bone marrow suppression was reversible. There were no other side effects such as thrombocytopenia, haemorrhagic cystitis, alopecia, or infections.

\section{Discussion}

Prolongation of cyclophosphamide treatment has been shown to induce a higher rate of long lasting remission; treatment for six weeks or less seemed to be less effective, ${ }^{17}$ and a higher cumulative dosage of cyclophosphamide than that used in our study has been reported to produce a long remission. ${ }^{2-7}{ }^{10}$ Because the complications of cyclophosphamide such as bone marrow suppression, ${ }^{211}$ gonadal toxicity, ${ }^{12}$ or oncogenicity ${ }^{4}$ are likely to be dose related, the two treatment protocols were compared for the treatment of children with steroid dependent nephrotic syndrome. In the present prospective study, the two treatment groups were comparable for clinical features, the mean duration of nephrosis, the mean number of relapses, and the mean cumulative dosage of prednisolone before entry, and the mean period of follow up after cyclophosphamide treatment. We found that the effect of an eight week course of cyclophosphamide on remission rate and its sparing effect on subsequent steroid therapy, if any, were the same as that of the 12 week course in children with steroid dependent minimal change nephrotic syndrome.
Several studies have reported separate evaluation of the effect of cyclophosphamide between non-steroid dependent and steroid dependent patients with minimal change nephrotic syndrome. ${ }^{8-10}$ In view of this, our data are comparable with these reports (table 3). Both Garin et $a l^{8}$ and Arbeitsgemeinschaft fur Padiatrische Nephrologie 9 found that non-steroid dependent nephrotic patients responded favourably, with prolonged remissions, to treatment for eight weeks or longer, whereas steroid dependent patients did not have such benefits. Nevertheless, a recent report of the same German group has shown that in steroid dependent patients with minimal change nephrotic syndrome, a 12 week course of cyclophosphamide at a dose of $2 \mathrm{mg} / \mathrm{kg} /$ day was associated with a significantly higher two year relapse free rate $(67 \%)$ than that after only an eight week course $(22 \%)$ (table 3). ${ }^{10}$ In contrast, the relapse free rate of our patients treated for eight weeks $(25 \%)$ was the same as that of those treated for 12 weeks (24\%) five years after the end of the treatment; these figures were comparable with those of steroid dependent patients treated for eight weeks in the two other reports. ${ }^{810}$ Of the 13 steroid dependent patients in the study of Garin et $a l^{8}{ }^{8}$ the three patients who did not relapse after cyclophosphamide were treated for either eight or nine weeks, but half of the other 10 patients who relapsed after the treatment were treated for 12 weeks or longer. These data support our contention that the use of cyclophosphamide for longer than eight weeks has no benefit in steroid dependent patients with minimal change nephrotic syndrome.

The reason for the difference in the effect of cyclophosphamide in steroid dependent patients with minimal change nephrotic syndrome between our results and those in the second German report is unclear. ${ }^{10}$ Their criteria for steroid dependence, the age at onset of nephrosis, and the number of relapses before cyclophosphamide treatment were similar to ours. The mean age at entry into the study of their patients treated for 12 weeks who had higher relapse free rate (approximately 9 years) was, however, similar to that of our total

Table 3 Cyclophosphamide in steroid dependent and frequently relapsing nephrotic syndrome

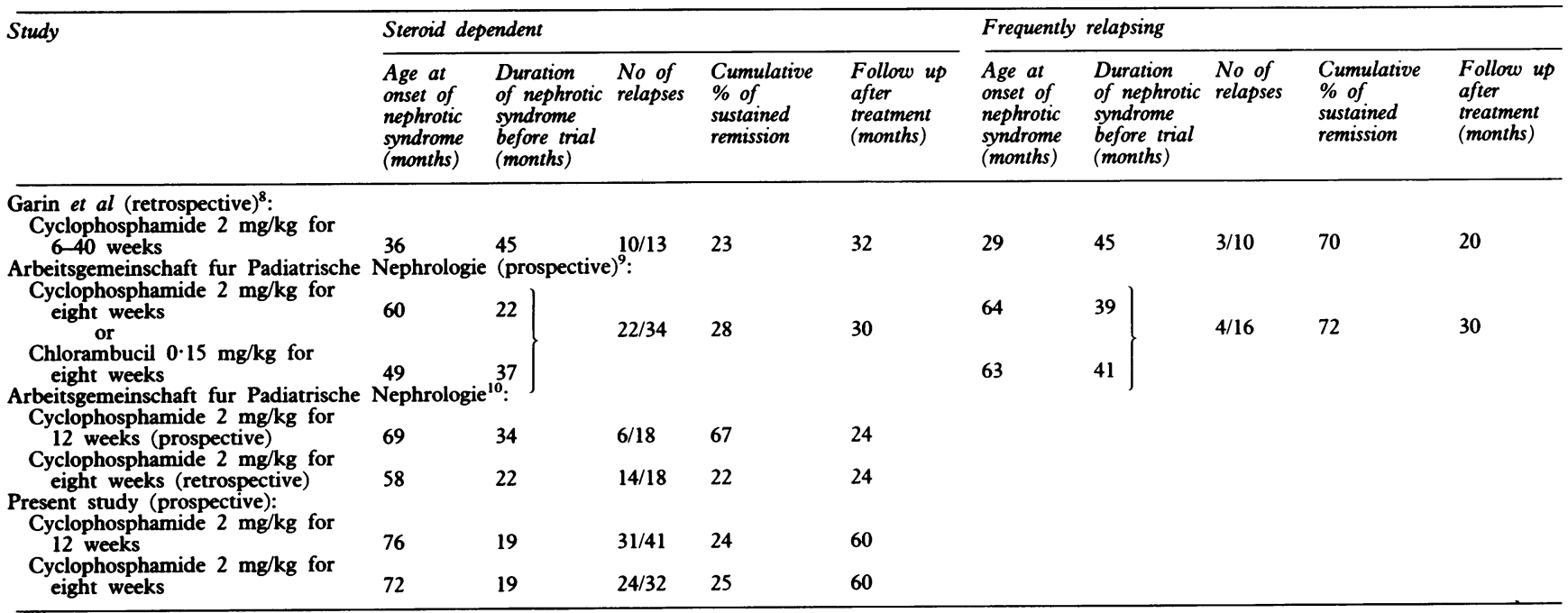


patients who did not relapse ( $9 \cdot 3$ years), but was higher than that of their patients treated for eight weeks (6.9 years) and of our total patients who did relapse $(7 \cdot 3$ years). Furthermore, all their patients who relapsed after cyclophosphamide did so within $\mathbf{4 0 0}$ days of the end of the course, but five of our patients relapsed later. Therefore the difference in age at the time that treatment was instituted or the period of follow up after treatment, or both, might account for the conflicting results-namely, the low cumulative percentage of sustained remission. The main factor determining the effect of cytotoxic treatment in steroid dependent patients with minimal change nephrotic syndrome seems to be primary resistance of the individual patient to the cytotoxic drugs, which may partly be related to the age at the time that treatment is instituted, as suggested by our study and that of Barratt et al. $^{6}$ In an era when an increasing number of immunosuppressive agents are being used for the treatment of steroid responsive or steroid dependent nephrotic syndromes, it should be emphasised that two to three year periods of follow up are necessary to assess the effect of a trial of such a drug.

The ultimate prognosis for children with frequently relapsing nephrotic syndrome is usually good, ${ }^{14}$ and exposure to the potentially serious toxic effects of cytotoxic drugs must be viewed with concern and kept as short as possible. Although we found no difference in the incidence of toxic reactions to cyclophosphamide between the two treatment protocols, there are insufficient data to determine the relationship between the dose and the duration of cyclophosphamide treatment and the degree of severity of long standing side effects on the reproductive system and the development of neoplasia. Therefore if cyclophosphamide has to be given to steroid dependent nephrotic patients because of unacceptable steroid toxicity or difficulty in controlling the disease, it should be used for no longer than eight weeks at a dose of $2 \mathrm{mg} / \mathrm{kg} /$ day to reduce the risk of development of late toxic effects as far as possible.

In summary, the effect of an eight week course of cyclophosphamide seems to be the same as that of a course of 12 weeks in children with steroid dependent minimal change nephro- tic syndrome. We conclude that cyclophosphamide should be used for no longer than eight weeks for the treatment of these patients. Nevertheless, it should be noted that the proportion of children with steroid dependent minimal change nephrotic syndrome who are likely to benefit from cytotoxic treatment is quite small.

We thank the paediatricians who referred patients to us for entry into the study and assisted in their management: Drs H Hayakawa, S Minowa, H Noguchi, M Okada, T Ozaki, M Tsuyuki, T Tsuzuki, and T Yazawa. We are also grateful to Drs M Chihara and T Nonoda for assistance in the collection of the data, and to Professor TM Barratt for reviewing this manuscript.

1 Barratt TM, Cameron JS, Chantler C, Ogg CS, Soothill JF. Comparative trial of 2 weeks and 8 weeks cyclophosphamide in steroid-sensitive relapsing nephrotic syndrome of
matiche mide in steroid-sensitive relapsing nephrotic
childhood. Arch Dis Child 1973;48:286-90.

2 McCrory WW, Shibuya M, Lu WH, Lewy JE. Therapeutic and toxic effects observed with different dosage programs of cyclophosphamide in treatment of steroid-responsive bu frequently relapsing nephrotic syndrome. F Pediatr 1973 82:614-8

3 International Study of Kidney Disease in Children. Prospective, controlled trial of cyclophosphamide therapy in children with the nephrotic syndrome. Lancet 1974;ii:423-7.

4 Cameron JS, Chantler C, Ogg CS, White RHR. Long-term stability of remission in nephrotic syndrome after treatmen with cyclophosphamide. Br Med 7 1974;iv:7-11.

5 Chiu J, Drummond KN. Long-term follow-up of cyclophosphamide therapy in frequent relapsing minimal lesion nephrotic syndrome. $\mathcal{F}$ Pediatr 1974;84:825-30.

6 Barratt TM, Bercowsky A, Osofsky SG, Soothill JF. Cyclophosphamide treatment in steroid-sensitive nephrotic syndrome of childhood. Lancet 1975; i:55-8.

7 Pennisi AJ, Grushkin CM, Lieberman E. Cyclophosphamide in the treatment of idiopathic nephrotic syndrome. Pediatin the treatment of idiop
rics $1976 ; 57: 948-51$.

8 Garin EH, Pryor ND, Fennell RS III, Richard GA. Pattern of response to prednisone in idiopathic, minimal lesion nephrotic syndrome as a criterion in selecting patients fo cyclophosphamide therapy. $\mathcal{F}$ Pediatr 1978;92:304-8.

9 Arbeitsgemeinschaft fur Padiatrische Nephrologie. Effect of cytotoxic drugs in frequently relapsing nephrotic syndrome with and without steroid dependence. N Engl F Med 1982; 306:451-4.

10 Arbeitsgemeinschaft fur Padiatrische Nephrologie. Cyclophosphamide treatment of steroid dependent nephrotic syndrome; coinparison of eight week with 12 week course. Arch Dis Child 1987;62:1102-6.

11 Feehally J, Beattle TJ, Brenchley PEC, et al. Modulation of cellular immune function by cyclophosphamide in children with minimal-change nephropathy. $N$ Engl $\mathcal{f}$ Med 1984; 310:415-20.

12 Etteldorf JN, West CD, Pitcock JA, Williams DL. Gonadal function, testicular histology, and meiosis following cyclophosphamide therapy in patients with nephrotic syncyclophosphamide therapy in patie
drome. $\mathcal{F}$ Pediatr 1976;88:206-12.

13 Armitage P. Statistical methods in medical research. Oxford: Blackwell, 1971:408-14.

14 Siegel NJ, Goldberg B, Krassner LS, Hayslett JP. Long-term follow-up of children with steroid-responsive nephrotic syndrome. $\mathcal{F}$ Pediatr 1972;81:251-8.

15 Ueda N, Chihara M, Kawaguchi S, et al. Intermittent versus long-term tapering prednisolone for initial therapy in children with idiopathic nephrotic syndrome. $\mathcal{F}$ Pediatr 1988; 112:122-6. 